\title{
Researching online communities of inquiry through digital ethnography
}

\author{
Neil Johnson, Faculty of Education and Social Sciences, University of Sunderland, UK.
}

\begin{abstract}
Research into providing effective online education has suggested an important goal for instructors is the creation of an online community of inquiry (CoI) where social, cognitive, and teacher presence are all important aspects of successful online learning. With reference to a recent reflective practice case study, this paper describes ways that the research on online communities of inquiry may be enriched through the use of digital ethnography. In the target reflective case study, data analysis tasks were designed and presented in an online VoiceThread site, promoting dialogic and multimodal engagement with data from actual research studies that are central to the module theme in teacher education. Interaction around these tasks is coded using the CoI framework. Ethnographic data from the participants was collected and coded using qualitative research protocols to contextualise the interaction data and provide a clearer understanding of how participants had come together throughout the module. The ethnographic data revealed some interesting concerns with online learning, including the use of technology as a barrier to participation.
\end{abstract}

\section{Introduction}

According to the latest figures, the number of students in higher education who are enrolled exclusively in an online programme has been growing steadily in recent years, and by 2016 was estimated to represent about 15 percent, or about one in six students [1]. Indeed, the online learning experience is developing so rapidly that it was also estimated that by 2017 , the proportion of all students taking at least one course online grew to 33.1 percent, from 31.1 percent in 2016 [1]. This dramatic rise in numbers, however, belies the fact that dropout rates for distance education are an increasing problem [2]. Research has shown that the recent rate of drop-out in open and distance learning systems are higher than drop-out in conventional learning environments [3].

Other studies have suggested that this drop-out trend poses an existential threat to open and distance education institutions $[2,4]$. In explaining this issue, there is some evidence that online students struggle with lower levels of motivation [5], and generally experience lower student satisfaction [6]. There has been related work that shows that many of the reasons for dropping out of an online education course relate to broader social issues with the students, and the fact that many of them are trying to combine full-time work, family responsibilities, and self-study [7]. That said, there is also an indication that the type of experience that an institution can offer to learners also greatly impacts on dropout rate. Croxton [8] suggests that learner-instructor interaction can have a decisive effect on student dropout. Berge [9] observes that a lack of online participation is a barrier for teacher educators and can have a negative impact, also. While there will always be circumstances beyond the control of the institution, it is clear that those involved in the delivery of distance learning need to fully understand the complexities of providing a satisfying and rich pedagogy, to maintain student interest and drive student learning. To further support this point, the amount of instructor-student interaction, learnercontent interaction, and internet self-efficacy, have all been found to be important predictors of student satisfaction [10].

The recent shift to online learning caused by the covid-19 crisis of 2020, has also meant that educators have an urgent need to better understand how to replace the face-to-face learning experience with synchronous and asynchronous digital activity.

The purpose of this paper is to report on a preliminary digital ethnography project created around developing an online and distance learning experience [11]. Specifically, the author has recently been tasked with rewriting and improving a module that sits within an MA TESOL Independent Distance Learning (IDL) program. By engaging with the task of re-writing and improving a distance learning module, much has been learnt about the processes of distance learning, distance teaching and the importance of effective task design and asynchronous interaction in and around pedagogical tasks. These reflections and insights will be discussed in the discussion and conclusion sections to this piece. 


\subsection{Distance Learning}

Anderson and Dron [11] describe distancepedagogy as constantly evolving, and as having gone through at least three definable generations of practice. They describe cognitivist, constructivist and now a connectivist pedagogy that assumes access to digital technology, and is an approach built around networked relationships and problem solving through information access and retrieval. Part of the challenge with teaching through distance, as we enter the so called 'network and connective future' [11], is to keep developing systems of practice that involve the distance learning student in a beneficial participatory practice within a community of online learners [12].

\subsection{Networked learning contexts}

Much attention has been paid to better understanding how communities come together in digital spaces, to better facilitate effective learning. An early investigation [12], tried to conceptualise what happens when learners interact successfully in an online platform. Their findings were developed into an influential model known as Community of Inquiry (CoI) that is comprised of three central, interdependent components: social presence, cognitive presence, and teaching presence. This has provided a much needed contextualized view of online teaching, in which the students, content, and instructors play a central role in creating the desired community. The model assumes that in the absence of face-to-face interaction in the classroom, participants in online distance learning must attempt to, "recreate the social and knowledge building processes that occur via the moment by moment negotiation of meaning found in the classroom" [13]. Research within this framework has largely focussed on understanding each of these three main constructs $[13,14]$ with researchers analysing the thematic content of postings online and coding the interactions according to function. For example, teacher presence can be broken down into interaction that serves to design and organize the learning process, facilitate discourse indicators, such as seeking to reach a consensus, and examples of direct instruction. Kehrwald [15] for further example, investigated social presence and was concerned with understanding the conditions under which learners demonstrate an understanding and willingness to participate in online interaction.

\subsection{The Digital Discussion Board}

The asynchronous discussion board is the key area for learner participation and interaction within many virtual learning environments (VLE). Discussion and threaded interactions around key topics have been highlighted as critical aspects of the learning process [16]. Researchers have tried to understand the behaviour and performance of students in and around these spaces, which are the most obvious places to try to track participation and learning. Walker, et al. [17] summarise much of this work and describe the distinction between 'lurkers', 'posters', and 'shirkers' as terms to encapsulate different modes of behaviour within an online community. Posters are those students who actively participate with postings and responses, while lurkers are seen as co-participants who read and can learn from the community, without actually contributing their own thoughts and ideas. Shirkers are the students who don't even log in or appear within the community, even though they have access to it. As Walker, et al. [17] comment, very little is known about these absent students, though in one study they were found to comprise as much as $40 \%$ of the total cohort [18].

\subsection{VoiceThread}

VoiceThread (VT), featuring text, audio and video comment sharing, was selected as the asynchronous discussion space for this project, primarily because it allows collaborators to make audio or video presentations, and to comment on individual or group video clips, images (e.g. photos and concept maps) through text, audio files, video, and drawings. These multimedia artefacts can help learners effectively construct understanding of target learning materials [19]. This multimedia capacity means that online collaboration using VT can be interactive and multimodal where learners can see and hear their collaborators in simulated asynchronous face to face interaction $[19,20]$. It is also compatible with the VLE that supported our online programs, allowing VT material to be placed into each study unit within the module. Learners were required to sign up to the site and to sign in once they accessed the links through Canvas.

\subsection{Digital Ethnography}

The development of computer-mediated communication as a major component of learning has led to the necessity for understanding the digital world as an ethnographic field site. This has opened up possibilities for the development of new research trajectories that changes the ethnographers' concern from one of place to one of mediated interaction [21]. As students experience communities and the construction of culture in online spaces, sometimes referred to as affinity spaces [22] so researchers have been keen to develop and understand the affordances of the digital world for ethnographic study. While Community of Inquiry (CoI) research has provided a very useful framework for understanding and organizing online instruction, I agree with Morgan [23] however, that the predominant use of content analysis methods in CoI has, for the most part, limited the focus to cataloguing, coding, and quantifying interaction, and has not yet taken a sufficient look at the contextual conditions in which the presence of all participants actually takes place. As a result, teaching recommendations are sometimes made that might not apply to diverse contexts. As Morgan [23] states, "Describing teaching presence as a negotiation within a mediated context requires a broader view of what instructors bring to the online context, how they position 
themselves and are positioned by others within it" (p.189). The same is also true, I would argue, for students negotiating online learning spaces. It is also my contention that there may be factors beyond the actual interaction that takes place, that can be recorded and analysed, and that impact meaningfully on the creation and outcome of the learning community.

In practical terms, ways of developing an online community has been widely discussed in the education media [24], as well as the distance learning literature [25] Practical suggestions have noted the importance of the medium that is used to stage learner-instructor interactions [25] and research has confirmed the importance of the instructor within the online community [13]. These factors were all considered as the content of the module in question was re-designed to improve the overall educational experience of the distance learners involved.

The tools that are packaged within a VLE such as Canvas, include detailed data on engagement and participation that would not be possible in face-to-face contexts. Interactions can also be stored, downloaded and analysed allowing for a precise view of what has been written and done within the learning space. Other research instruments such as questionnaires can also be seamlessly built into a VLE, potentially providing the researcher with a fuller and robust view of what has occurred in any online learning space.

\section{The Study}

As mentioned above, the background to the study is an ongoing effort to better understand online education, and to ultimately provide a more effective and transformative learning experience for distance learners on an MA TESOL IDL program.

\subsection{The context: teacher training through IDL}

The optional module on the MA TESOL program Theories of Second Language Learning was offered online in the spring semester from January, 2019 until the final submission of assignments was complete in May of that year. The program is structured as below in Table 1.

\begin{tabular}{|l|l|l|}
\hline $\begin{array}{l}\text { Phase of } \\
\text { Program }\end{array}$ & Modules & Timing \\
\hline Certificate & $\begin{array}{l}\text { Principles and } \\
\text { Practice } \\
\text { Linguistics for } \\
\text { ELT }\end{array}$ & $\begin{array}{l}\text { October - } \\
\text { January }\end{array}$ \\
\hline Diploma & $\begin{array}{l}\text { Theories of } \\
\text { Second } \\
\text { Language } \\
\text { Learning } \\
\text { The Research } \\
\text { Process }\end{array}$ & $\begin{array}{l}\text { January - May } \\
\text { September }\end{array}$ \\
\hline Masters & Dissertation & $\begin{array}{l}\text { October - } \\
\text { February }\end{array}$ \\
\hline
\end{tabular}

Table 1. Overview of program

The IDL module ran in parallel with the on campus course that was taught over 12 weeks with two 2-hour sessions per week. In the iteration of the course in question, there were a total of 26 students taking the module by distance. The learners were distributed around the world in China, Japan, USA, other parts of the UK, as well as the Middle East and Africa. The module is housed as a course in the VLE known as Canvas, and learners are added to the module upon selection of their optional module for the second phase of the MA program. The module is organised chronologically in the Canvas site with students introduced to the dominant cognitive paradigm in second language theory, before tackling short units, designed to last approximately one week, through material posted in Canvas under each subject-heading. The students cover a total of 10 units, completing the module with a look at Complexity theory, one of the most contemporary theories in the field. Students were instructed to download the main pdf file which contains content reading and questions as described in more detail below, and work through suggested readings at their own pace and in their own time. Included in each unit, in keeping with our redesign, were video recordings of the lecture slides, related questions for discussion posted within the slides, and related learning tasks that were designed to facilitate participation, stimulate discussion, and engender more discovery based interactional sequences, as described above. By having students respond to images and data from representative studies, it was hoped that they would feel valued as contributors to the growing understanding that may be distributed throughout the group. Ultimately, it was hoped that this experience would provide a powerful and effective learning experience for these teacher trainees. The following research questions then guided the investigation in the digital ethnography project: How did learners respond to the invitation to greater participation in the IDL discussion spaces? What aspects of instructor - media - learner interaction were/were not effective? 


\section{Methodology}

A discourse-centered online ethnographic methodology was adopted [21] in order to better understand the complex ways that instructors and students interacted throughout the trajectory of the module. Learners were provided a range of academic tasks that were posted each week in the VT platform. Regardless of the task, the students' part of the interaction was to respond to the questions that were posed, and they were also invited to make any further comments and/or respond to the postings of others. The core of the task on each occasion was a recorded lecture that was put together around Powerpoint slides and recorded using Panopto technology. Following from the narrative thread from the lecture, there were data analysis tasks and other research quotes to respond to. These were threaded and were visible to all participants within the group. The hope at the outset was for learners to share their thoughts about the material and extend the learning sequences away from reliance on the lecture and the readings, also available in the VLR. At the conclusion of the module, all interactions were recorded and placed into a table (Table 2) so that a sense of participation level could be gained. Postings from the VT site were downloaded, placed into a word file and organized according to topic. An example topic was then coded for both social presence and cognitive presence using the CoI framework [12] and the coding definitions developed in the literature [13] (see Appendix A). The aim here was to gain a finer grained understanding of what was going on within these discussions. The participants were also offered a detailed questionnaire on their experience as learners with the VT system and how the module had progressed from their perspective. The comments and other feedback received through email and course feedback were collated and coded using a thematic coding consistent with qualitative data analysis protocols [26]. The data was coded independently and then the findings were discussed with a co-researcher to refine the categories, and themes and discuss any inconsistencies with the coding process. This data was used to contextualise the online interaction data [27]. Within the data collected, exemplar interactions were chosen to highlight themes that emerged from the overall data set.

\section{Results}

The overall interaction patterns throughout the twelve weeks are captured by data in the VLE and are shown in Table 2 below. The data suggests that a significant number of the students contributed to and also observed the postings that took place throughout the semester. There is a noticeable drop-off in activity towards the end of the module, with the peak of activity taking place between week 1 (self-introductions) and week 9 (identity theory). Seven out of the 26 students did not contribute any posting throughout the 12 weeks of the module.

\begin{tabular}{|c|c|c|c|}
\hline Theme of Unit & Posters & Posts & Views \\
\hline $\begin{array}{l}\text { Self- } \\
\text { Introductions }\end{array}$ & 19 & 28 & 61 \\
\hline $\begin{array}{l}\text { The Monitor } \\
\text { Model }\end{array}$ & 14 & 35 & 47 \\
\hline $\begin{array}{l}\text { Acculturation } \\
\text { Theory }\end{array}$ & 12 & 49 & 55 \\
\hline $\begin{array}{l}\text { Interaction } \\
\text { Hypothesis Task }\end{array}$ & 17 & 18 & 36 \\
\hline $\begin{array}{l}\text { Sociocultural } \\
\text { Theory } 1\end{array}$ & 14 & 9 & 27 \\
\hline $\begin{array}{l}\text { Sociocultural } \\
\text { Theory - Task } 1\end{array}$ & 9 & 20 & 26 \\
\hline $\begin{array}{l}\text { Sociocultural } \\
\text { Theory - Task } 2\end{array}$ & 16 & 24 & 28 \\
\hline $\begin{array}{l}\text { Sociocultural } \\
\text { theory - Task } 3\end{array}$ & 16 & 24 & 18 \\
\hline Identity Theory & 18 & 42 & 26 \\
\hline Assignment 1 & 16 & 35 & 68 \\
\hline $\begin{array}{l}\text { Communities of } \\
\text { Practice }\end{array}$ & 0 & 0 & 9 \\
\hline Assignment 2 & 2 & 8 & 29 \\
\hline $\begin{array}{l}\text { Complexity } \\
\text { Theory }\end{array}$ & 0 & 0 & 0 \\
\hline
\end{tabular}

Table 2. Overview of VoiceThread Interaction

\subsection{Discourse in Example VT Discussion}

The discussion around Acculturation Theory was selected for coding and detailed analysis because it was the discussion with the most contributions that allows highlighting of the interaction features that are common to all of the interactions that took place over the 12-week period. The coding in Appendix A highlights the factor of social presence within the discussions. The coding categories and definitions have been adapted from Shea et al, [13]. The category of 'social presence' was of particular interest within VT since development of professional identities is an overriding concern in teaching this module.

\subsection{Ethnographic Data}

As described in the methodology section, the data from student feedback and the online questionnaire was collected and coded for important themes [26]. The 
following four themes emerged from the data and examples of data from each theme are provided below.

\section{Theme 1: Positive Learning Experience}

Very useful. I enjoyed the video lectures and the discussions. They were far more interactive than Canvas. The conversations were lively; response to comments by tutors were quick, the black background for me makes the platform warm unlike Canvas which I found austere.

It helped to reduce the isolation I had felt as a distance learner. The interactive nature of it, being able to make and see others' comments, engendered a more social experience.

Using voice thread give me the opportunity to rehearse what I have already learned. I preferred to watch and listen more than participating.

I found the preparation/discussion for assignments useful.

I prefer reading others' comments. They helped understand the topic better. The comments from other students opened my eyes to other perspectives.

Voice over slides increased my engagement levels and made the info more accessible. I enjoyed the text comment function.

It enriches my memory. The spoken text over lecture slides was extremely useful, the others less so. I enjoyed hearing the lecturer's voice and comments; which gave me a deeper understanding than just reading.

\section{Theme 2: Positive Positioning}

Thanks - I really enjoyed VoiceThread - it really helped me but more than that it made me feel part of a community. This was lacking in the first modules for me.

I enjoyed the picture task and text - looking at original quotes from the literature and making sense of them sharing ideas and thoughts. This is what I imagined I would be doing - like, now I'm an MA student for real!

In VoiceThread we enjoyed really good discussion with all staff and students coming together. This was more like a community coming together and I learnt so much from reading and taking part. This made me think about my teaching and myself as a teacher - do I understand theory enough? No - I want to be taking part in the conversations in my field or my area. This was good practice for that time!

VoiceThread meant we could go past the material and into our own experiences much more. I wanted to share my own experience and read about the others.
This was very useful for me. I got more confidence by sharing my ideas more. I want to feel like I am a professional and share with other professionals in TESOL.

\section{Theme 3: Negative Experience - Technology/technical Related}

I found it difficult to sign up and found most of the content I needed on canvas.

I did, but didn't enjoy it. I preferred to read text and not $\log$ onto another website to be told information. (Sorry)

However, the text comments were less helpful as the time between asking and answering was too long and I lost the thread.

Initial teething problems with set up. It would be an idea to give clearer explanations as to how to set up a VT account and with which email address. Annoyingly it only works well with Chrome.

Many comments or slides were timed, and if you didn't let the entire time elapse (e.g. you read the comment quickly and moved on to the following slide); the slide/comment would remain marked as unread. This was really irritating, because for ages I would $\log$ in and think there was new material and hunt around for it, only to find that there wasn't. Admittedly, this could just be my inability to grasp its proper usage.

\section{Theme 4 -Time Constraints}

My usage trailed off towards the end because of the notification system.

I don't have time to use the extra site. Actually, I never used it. I just want to get to the assignments.

It would be useful for those with lots of time available to access the information and make timely contributions. I work full-time and therefore I have set days/times for studies. Therefore, I found the interaction less helpful as it did not always suit the time o had available to study.

I found it frustrating because I don't have time to study the material so much - I just want the easy access to PPT.

I didn't find it useful. I preferred just using the texts/answers/information on each module. It's difficult when working overseas. I don't have enough time for this extra activity.

I find discussions difficult too, due to a busy schedule working overseas.

Waiting for permission to access the presentations. This was unhelpful because the information wasn't available to me at the time that I needed it. I can't waste my time in this way. 


\section{Discussion/Conclusions}

This digital ethnography has provided several insights into distance learning and online education. First of all, from a research perspective, it is clear that the broader view of activity within the module that is provided by the questionnaire and interaction data provides a much fuller picture of how the re-designed pedagogy has impacted upon the student experience. The high levels of engagement of a majority of the students, and sustained interest across most of the module was encouraging, and supports the findings from the CoI framework. Indeed, the examples of interaction (see Appendix A) in the data show all the characteristics of high social presence (e.g. vocatives, humour, instruction) and this was a positive in finding the study.

Several students reported encouragingly that they felt the experience with VT had been positive and, importantly, that they felt they were being positioned positively as researchers and professionals. This is clearly conveyed in theme 2 from the ethnographic data.

However, the feedback from the students highlighted the often harsh reality of working on an education program by distance. MA TESOL serves as an important marker of professional development, and for our students is a qualification most often sought while working full-time. The on campus students, who meet face-to-face each week, are usually studying fulltime. The difficulty of reproducing the on campus experience through virtual interaction, was really brought into focus by the online interaction data, and the responses to the questionnaire. There is concern, for example, that several students within the cohort were not able to participate at all in our online community. As has been found in previous research [18] it is not uncommon for a large percentage of students to not be engaged in the teaching/learning activities of a course module. Perhaps ironically of course, these members of the cohort also failed to respond to the questionnaire and so it was impossible to gain any understanding of what the barriers were for them. Further research will be needed to better understand the so called 'shirkers' and what motivates them to pay expensive fees and yet not engage fully with the learning experience that they have paid for.

There is some evidence in theme 4 detailed above, for example, that for some students, doing the program might be more about achieving a qualification rather than professional development, as such. The idea of 'just wanting to get to the assignments' that one participant suggested in their feedback is indicative of such an attitude. Related to that notion is the sense that time itself is a very important factor for some of these students. Naturally, studying by distance often involves working a full-time job as well as attending to family and other social concerns. Again, further research is required to better understand the motivation and constraints that such students have to work with.

There is some evidence that the technology itself, within such a context, can prove to be an unsurmountable barrier to participation. With VT, though embedded within Canvas, did not provide a seamless experience. Learners had to log in to another site and remember another password. There could be issues with access due to wi-fi efficiency or other technology hardware related issues. In several cases, this barrier was enough to mean that learners reported that they could not actively participate. This finding is in keeping with previous research [28] where internet experience and efficacy have been found to be a strong indicator of performance.

The findings have highlighted the fact that while it is commonly assumed that interaction is a positive thing for educational practice, a more nuanced understanding is required of how such interaction occurs, and who takes part and who doesn't. There was evidence that the more constructivist pedagogy espoused in the redesign of the module describer here, was effective to better position students as professionals and near peers. Having the texts and tasks integrated with the discussion, rather than more remotely on an asynchronous discussion board is perhaps one positive that can be taken from the VT experience. However, the next step in researching asynchronous discussion boards, through digital ethnography, must be to better understand the students who do not take part in the online community of inquiry.

\section{References}

1. Inside Higher Education.

https://www.insidehighered.com/digitallearning/article/2018/11/07/new-data-onlineenrollments-grow-and-share-overall-enrollment. (2018). Accessed, January 15, 2020.

2. A. Cohen, Educational Technology Research and Development, 65(5), 1285-1304, (2017).

3. W. Boston, P. Ice, \& M. Burgess, Online Journal of Distance Learning Administration, 15(2), 1-6. (2001).

4. O. Simpson, Open Learning: The Journal of Open, Distance and e-Learning, 28(2), 105119. (2013).

5. S. Carr, Chronicle of Higher Education, 46 (23), (2000).

6. J. Kenny, ultiBASE Articles. Retrieved January 30, 2020, from http://ultibase.rmit.edu.au/ Articles/march03/kenny2.pdf. (2003) 
7. A. Ashby, Open Learning: The Journal of Open, Distance and e-Learning, 19(1), 65-77. (2004).

8. R. A. Croxton, Quarterly Review of Distance Education, 15(2), 61. (2014).

9. G. A. Berg, Lessons from the edge: For-profit and nontraditional higher education in America. (2005).

10. Y. C. Kuo, A. Walker, K.E. Schroder \& B. R. Belland, The internet and higher education, 20, 35-50. (2014).

11. T. Anderson, \& J. Dron, The International Review of Research in Open and Distributed Learning, 12(3), 80-97. (2011).

12. D. R. Garrison, T. Anderson, \& W. Archer. American Journal of distance education, 15(1), 7-23. (2001).

13. P. Shea, S. Hayes, J. Vickers, J., M. GozzaCohen, S. Uzuner, R. Mehta, \& P. Rangan, The Internet and Higher Education, 13(1-2), 10-21. (2010).

14. J. B. Arbaugh, The International Review of Research in Open and Distributed Learning, 9(2). (2008).

15. B. Kehrwald, Distance Education, 29(1), 89106. (2008).

16. D. Carrasco, T. Irribarra, Teaching Tolerance in a Globalized World. IEA Research for Education. Vol 4. Springer. (2018).

17. B. Walker, J. Redmond, \& A. Lengyel, eCULTURE, 3(1), 16. (2010).

18. C. Egan, A. Jefferies \& J. The Electronic Journal of e-Learning, 4(1), 15-24. (2006).

19. Y. C. Hsu, Y. H. Ching, \& B. L. Grabowski, Handbook of research on educational communications and technology (pp. 747-758). Springer, New York, NY. (2014).

20. J. Kidd, Society for Information Technology \& Teacher Education International Conference, 2158-2162. (2013).

21. J. Androutsopoulos, J, Language@ internet, 5(8). (2008).

22. J. P. Gee, Educational Technology, 27-31. (2017).

23. A. L. Morgan, Investigating our experience in the world: A primer on qualitative inquiry. Univ. of Tennessee Press. (2011).

24. A. Mishra, British Journal of Educational Technology, 33(4), 493-496. (2002).
25. P. A. Kurzman, Journal of Teaching in Social Work, 33(4-5), 331-338. (2013).

26. D. A. Friedman, D. A. Research methods in second language acquisition, 180. (2012).

27. M. Hauck, R. Galley \& S. Warnecke, The Routledge handbook of language learning and technology (97-113). Routledge. (2016)

28. A. Kundu. Asian Association of Open Universities Journal. (2020). 
Appendix A: Example coding of VoiceThread Interaction for Social Presence - Acculturation Theory Unit

\begin{tabular}{|c|c|c|c|c|}
\hline \multirow[t]{7}{*}{$\begin{array}{l}\text { Social } \\
\text { Presence in } \\
\text { VoiceThread }\end{array}$} & $\begin{array}{l}\text { Social Presence } \\
\text { (Categories) }\end{array}$ & Indicators & Definition & Examples \\
\hline & Affective & Expressing emotions & $\begin{array}{l}\text { Conventional } \\
\text { expressions of emotion }\end{array}$ & $\begin{array}{l}\text { However, to my surprise, my } \\
\text { Korean only stayed on day to day } \\
\text { surviving level after two years, } \\
\text { just like Alberto. }\end{array}$ \\
\hline & & Use of humour & $\begin{array}{l}\text { Teasing, cajoling, irony, } \\
\text { sarcasm, understatements }\end{array}$ & $\begin{array}{l}\text { If you are familiar with the U- } \\
\text { curve which illustrates the phases } \\
\text { of culture shock, I got stuck at the } \\
\text { bottom of the curve for a while! }\end{array}$ \\
\hline & & Self-disclosure & $\begin{array}{l}\text { Details of life outside of } \\
\text { class - likes, dislikes, } \\
\text { preferences }\end{array}$ & $\begin{array}{l}\text { I've lived in the UAE for } 6 \text { years } \\
\text { now }\end{array}$ \\
\hline & & $\begin{array}{l}\text { Use of unconventional } \\
\text { expressions to express } \\
\text { emotion }\end{array}$ & $\begin{array}{l}\text { Unconventional } \\
\text { expressions of emotion. } \\
\text { Includes repetitious } \\
\text { punctuation, conspicuous } \\
\text { capitalization, emoticons. }\end{array}$ & $\begin{array}{l}\text { Thanks for your stimulating } \\
\text { questions :) }\end{array}$ \\
\hline & & Expressing value & $\begin{array}{l}\text { Expressing personal } \\
\text { values, beliefs and } \\
\text { attitudes }\end{array}$ & $\begin{array}{l}\text { I do not see how learning Arabic } \\
\text { will add value to me if I do return } \\
\text { to my home country. }\end{array}$ \\
\hline & $\begin{array}{l}\text { Open } \\
\text { Communication }\end{array}$ & $\begin{array}{l}\text { Referring to other's } \\
\text { messages }\end{array}$ & $\begin{array}{l}\text { Direct references to } \\
\text { contents of others' posts }\end{array}$ & $\begin{array}{l}\text { Hi Student } 1 \& \text { Instructor } 1 \text { - some } \\
\text { interesting issues raised here. As } \\
\text { pointed out 'motivation' and its } \\
\text { role in SLA is a popular area of } \\
\text { research. I agree with instructor } \\
1 \text { 's comment about qualitative } \\
\text { research }\end{array}$ \\
\hline & & Asking Questions & $\begin{array}{l}\text { Students ask questions of } \\
\text { other students or other } \\
\text { participants }\end{array}$ & $\begin{array}{l}\text { Was Schumann at any point } \\
\text { concerned about accuracy? }\end{array}$ \\
\hline & & Complimenting & $\begin{array}{l}\text { Complimenting others or } \\
\text { contents of } \\
\text { others' messages }\end{array}$ & $\begin{array}{l}\text { This has been a very fascinating } \\
\text { read and discourse }\end{array}$ \\
\hline & & Expressing agreement & $\begin{array}{l}\text { Expressing agreement } \\
\text { with others or contents of } \\
\text { others messages }\end{array}$ & $\begin{array}{l}\text { Similar to what Student A's } \\
\text { experience, when I was in Korea } \\
\text { for two years, I've never felt the } \\
\text { needs to learn their language. }\end{array}$ \\
\hline & & Personal advice & $\begin{array}{l}\text { Offering specific advice } \\
\text { to classmates }\end{array}$ & $\begin{array}{l}\text { I would recommend reading into } \\
\text { Language Socialization } \\
\text { approaches to SLA }\end{array}$ \\
\hline & $\begin{array}{l}\text { Group } \\
\text { Cohesion }\end{array}$ & Vocatives & $\begin{array}{l}\text { Addressing or referring } \\
\text { to the } \\
\text { participants by name }\end{array}$ & $\begin{array}{l}\text { Similar to you Instructor } 1 \text { - when } \\
\text { first arriving in Korea I was } \\
\text { totally flummoxed by the } \\
\text { language }\end{array}$ \\
\hline & & $\begin{array}{l}\text { Addresses or refers to } \\
\text { the group using } \\
\text { inclusive pronouns }\end{array}$ & $\begin{array}{l}\text { Addresses the group as } \\
\text { we, us, } \\
\text { our, group }\end{array}$ & $\begin{array}{l}\text { We will look at Eva Hoffman's } \\
\text { book in the unit on identity a little } \\
\text { later in the module. }\end{array}$ \\
\hline & & $\begin{array}{l}\text { Phatics, salutations and } \\
\text { Greetings }\end{array}$ & $\begin{array}{l}\text { Communication that } \\
\text { serves a purely social } \\
\text { function; greetings or } \\
\text { closures }\end{array}$ & $\begin{array}{l}\text { Hi all, } \\
\text { Sorry I've joined in rather late }\end{array}$ \\
\hline & & Course reflection & $\begin{array}{l}\text { Reflection on the course } \\
\text { itself }\end{array}$ & $\begin{array}{l}\text { Thank you, these slides plus } \\
\text { narration really help! }\end{array}$ \\
\hline
\end{tabular}

